\title{
Evaluation and Comparison of Currently Available Fluorescence Immunoassay (FIA) Test with Rapid Immuno Chromatographic Test (ICT) Considering NS 1 ELISA as a Reference Test
}

\author{
J.A. Pohekar*, M.H. Bhalchandra, H.S. Ghogre and T.G. Pathrikar \\ Department of Microbiology, MGM's Medical College and Hospital, Aurangabad, India \\ *Corresponding author
}

\section{A B S T R A C T}

Dengue is one of the rapidly emerging diseases globally. Early diagnosis can improve clinical outcome by ensuring close follow up, initiating appropriate supportive treatment and increasing awareness of hemorrhage and shock. Many diagnostic kits are available commercially. Amongst these gold standard test is $\operatorname{IgM}$ and IgG ELISA with seroconversion, but we can advice this test only after 5 days when the antibodies will start developing. Nonstructural glycoprotein 1 (NS-1) is considered to be a useful marker for early diagnosis of dengue, as this can be advised early. NS 1 ELISA is carried out only in

\section{Keywords}

Dengue, FIA, ELISA, ICT, NS 1 Antigen.

Article Info

Accepted:

07 September 2017

Available Online:

10 November 2017 institutional laboratories where technical expertisation as well as specific machines are available. So, for a routine laboratory with limited resources rapid ICT test is a better choice. In the present study the currently available Fluorescence immunoassay (FIA) test is evaluated and compared with rapid ICT considering NS 1 ELISA as a reference test. To evaluate the currently available fluorescence immunoassay test for detection of Dengue NS 1 antigen. To compare the currently available Fluorescence immunoassay (FIA) test for detection of Dengue NS 1 antigen with rapid ICT test and Microwell ELISA test. Cross sectional observational study. In this study, 200 samples from dengue suspected patients are tested for presence of NS 1 antigen by rapid ICT test. From these 50 positive and 50 negative samples are further retested by NS 1 ELISA and NS 1 by FIA. Results are analyzed and compared with each other. NS 1 ELISA is considered as a reference test and NS 1 Fluorescence immunoassay and rapid ICT as an index tests. Data is analyzed and sensitivity, specificity, positive predictive value and negative predictive value are derived for each test. FIA test is more specific and having positive predictive value of $97.43 \%$ which states that it is more reliable than rapid ICT. FIA is less time consuming and easy to perform whereas Microwell ELISA is time consuming and require highly technical expertise. NS 1 Microwell ELISA and FIA results are very much comparable with each other. Whereas false positive less with FIA and more with rapid ICT card test.

\section{Introduction}

Dengue is an important arthropod borne viral disease, transmitted by Aedes aegypti mosquito, ${ }^{(1)}$ affecting tropical and subtropical regions. ${ }^{(2,3)}$ It is one of the rapidly emerging disease globally, ${ }^{(1)}$ affecting 100 million people/year, of which 5,00,000 cases presenting with dengue hemorrhagic fever and resulting in around 30,000 deaths mostly among children. ${ }^{(2)}$ Early diagnosis can improve clinical outcome by ensuring close 
follow up, initiating appropriate supportive treatment, and increasing awareness of hemorrhage and shock. Dengue disease is caused by one of four closely related but antigenically distinct virus serotypes DENV 1, DENV 2, DENV 3, and DENV 4 of genus flavivirus. ${ }^{(2,4,5,6)}$ The dengue viral genome is positive sense, enveloped, single stranded RNA virus, approximately $11 \mathrm{~kb}$ in size. $(1,2,5,6,7)$ It contains 10 genes of 3 structural proteins (capsid C, membrane M, envelope E) and of seven Non Structural proteins NS1, NS2a, NS2b, NS3, NS4a, NS4b, NS5. ${ }^{(1,2,4,6)}$ NS 1 is glycoprotein released from dengue virus infected cells, involved in virus replication. ${ }^{(2,3,5,6,7,8)}$ It is hexameric soluble protein released during infection and accumulate in higher concentrations upto 50 $\mu \mathrm{g} / \mathrm{ml}$, which is detectable in primary as well as secondary infections in early phase. ${ }^{(2,5)}$ Clinically fever starts with malaise, chills and headache, soon leads to backache, joint pain, muscular pain and pain behind the eye ball.

Temperature persists for 3 to 5 days or may raises in about 5 to 8 days (saddle back fever). Myalgia is severe with deep bone pain, which characteristic of fever (break bone fever). Dengue manifest in three forms, dengue fever (DF), dengue hemorrhagic fever (DHF), and dengue shock syndrome (DSS). ${ }^{(9)}$ Infection with one of four serotypes provide immunity to only that serotype for life. Reinfection with different serotype after primary attack is more dangerous causes DHF. Majority infections are self-limiting, subside on its own.

Death is a rare event. ${ }^{(10)}$ Patient may present with decreased blood cells like leucopenia (<4000/cumm) / thrombocytopenia (<one lakh/cumm), petechiae, ecchymosis / purpura, mucosal bleeding / epistaxis / bleeding gums, hemetemasis / malena, > 20\% rise in HCT for age/sex. Release of cytokines, release of vasoactive mediators, release of procoagulants, may manifest as disseminated intravascular coagulopathy, with signs of plasma leakage like - Pleural effusion, Ascites, Hypoproteinemia. ${ }^{(10)}$

Currently there are three basic methods for diagnosis in laboratories, these are virus isolation, detection of viral genome by RTPCR and detection of dengue virus specific antibodies and detection of NS 1 antigen.

\section{Diagnostic tests ${ }^{(1)}$}

Serology

Identification - RT PCR

Isolation - Virus culture

\section{Disease monitoring tests}

White Blood Count

Haematocrit value

Platelet count

Liver Function Tests

Analysis of paired acute and convalescent rise in sera to show four fold rise in antibody titer by ELISA is the most reliable evidence of an active dengue infection. ${ }^{(6)}$

NS 1 is non-structural protein present in febrile phase from day 0 to day 9 , generally persist upto 15 days. ${ }^{(11)}$ IgM antibodies are not detectable until 5 to 10 days in primary infection and day 4 to 5 days in secondary infection after onset of illness. IgG antibodies appear after 14 days and persist for life in primary infection and rise within 1 to 2 days after the onset of symptoms in secondary infection. NS 1 is considered to be a useful marker for early diagnosis of dengue. Estimated by Rapid ICT and Microwell ELISA methods. Rapid ICT gives false positives with Ebstein Barr virus, Malaria, Rheumatoid factor, Leptospirosis, Japanese encephalitis, Yellow fever and West Nile virus. ${ }^{(10,11)}$ NS 1 is considered to be a useful marker for early diagnosis of dengue 
infection. In routine laboratories rapid ICT (immunochromatographic test) is the test of choice, as ELISA (Enzyme Linked Immunosorbant Assay) tests require technical expertisation and special equipments, while PCR (Polymerase Chain Reaction) and viral cultures are expensive and are carried out in reference laboratories where facilities are available. Serological tests may give false positive (cross reactivity) / false negative (related to time of testing) results. PCR is only available in few centers where special equipments and trained personnel are available and it is more expensive. Virus isolation has poor yield, difficult to isolate, time consuming and require special lab equipped with tissue and virus isolation, and it is also more expensive.

The present study was aimed to evaluate the currently available FIA test, which is being made available and is being evaluated at different centers, as per the request of manufacturer, the test have been evaluated by testing samples detecting NS 1 Antigen simultaneously by FIA, Microwell ELISA and Rapid ICT card tests.

\section{Aims and objectives}

To evaluate the currently available fluorescence immunoassay test for detection of dengue NS 1 antigen.

To compare the FIA test for detection of NS 1 Antigen by rapid ICT and ELISA tests.

\section{Materials and Methods}

Duration of study: $1^{\text {st }}$ September 2016 to $20^{\text {th }}$ September 2016.

Design: Cross sectional observational study.

Total 200 samples from dengue suspected patients from tertiary care hospital, collected during $1^{\text {st }}$ September 2016 to $20^{\text {th }}$ September 2016 (this was the period when many cases of dengue were there) were tested with rapid ICT to detect NS 1 antigen. Out of 200, 59 were positive for either NS 1, IgM and/or IgG and 141 were negative by rapid ICT. From 59 positive samples, 46 were positive for NS 1 Ag only, 4 were for NS1+IgM, 6 were for $\operatorname{IgM}, 2$ were for $\operatorname{IgM}+\operatorname{IgG}$ and 1 was positive for IgG. Out of 200 samples 50 NS 1 positive and first 50 negative samples were further tested for detection of NS 1 antigen by Microwell ELISA and by fluoroscence immunoassay (FIA). Only IgM, Only IgG, and $\operatorname{IgG}$ and $\operatorname{IgM}$ positive samples were excluded from this study. The kits were supplied by J.mitra and Co. Pvt. Ltd. In this study Microwell ELISA test was considered as a reference test and FIA and ICT were as index tests. Only IgM, Only IgG, and IgM and $\operatorname{IgG}$ positive were excluded from this study. In this study Microwell ELISA test was considered as a reference test and FIA and ICT were as index tests.

\section{NS 1 by FIA}

It is dengue NS 1 antigen Quanti card. It detects dengue NS 1 antigen qualitatively in human serum/whole blood/plasma. It is sensitive immune-chromatographic test with iQuant Analyser. It is fluorescence immunoassay based on sandwich principle. In this kit test area is coated with specific anti dengue NS 1 antigen antibodies. When sample added, if dengue NS 1 antigen is present, it forms a complex with another specific NS 1 antibodies conjugate to fluorochrome. After addition of assay buffer, complex formed migrates along nitrocellulose membrane to the test region and antibodyantigen-antibody fluorescence immunocomplex is formed. Which is detected by iQuant analyser and results will be displayed on screen. Care should be taken of QR code, anything should not be 
stuck/written on it, which leads to erroneous results. It is only operational with iQuant analyser. Advantages are - we can use fresh finger prick blood, only $5 \mu$ l sample is required, easy to perform, less time required as compared to ELISA.

\section{Procedure}

$5 \mu 1$ of whole blood/serum/plasma is added in well ' $\mathrm{S}$ '. Avoid spillage on $\mathrm{QR}$ code. Add three drops of assay buffer in well 'B'. Allow to react for 25 mins. Then insert this kit into iQuant analyser with arrow $\longleftarrow$ towards analyser. Then press 'RUN' icon. Note value on the screen. Do not read after 25 mins.

\section{NS 1 by Microwell ELISA}

Here there is in vitro qualitative detection of dengue NS 1 antigen in human serum/plasma. It detects all four serotypes of dengue virus. It is solid phase enzyme linked immunosorbant assay (ELISA) based on 'Direct sandwich' principle. Microwells are coated with antidengue NS 1 antibodies with high reactivity for dengue NS 1 antigen. Dengue NS 1 antigen from sample is trapped / sandwiched between antibody and Horse Reddish Per Oxidase conjugate antibody. Amount of bound peroxidase gives concentration of dengue NS 1 antigen. Addition of substrate buffer and chromogen develops blue colour. Intensity of developed colour is proportional to the concentration of dengue NS 1 antigen in the sample. After addition of stop solution yellow colour develops which is read at 450 nm spectrophotometrically. ${ }^{(13)}$

\section{Rapid ICT}

It is rapid visual test for detection of NS 1 antigen and differential detection of $\operatorname{IgM}$ and IgG antibodies in human serum/plasma. It is based on antigen-antibody reaction. The kit contains two devices containing testing for
NS 1 antigen and $\operatorname{IgM} / \operatorname{IgG}$ antibodies. The tests are run following manufacturer's instructions. If NS 1 antigen present in sample this antigen forms Antigen antibody complex that migrates along the membrane to the test region and forms the visible pink line at $\mathrm{T}$ region as antigen antibody gold conjugate complex. ${ }^{(12)}$

Interpretation: Reactive: $1 \mathrm{U}$ and above. NonReactive: $<1$ U. ${ }^{(11)}$

\section{Results and Discussion}

50 negative samples by rapid ICT were also negative by Microwell ELISA and FIA.

The sensitivity, specificity, positive predictive value, and negative predictive value were calculated for Rapid ICT and FIA considering Microwell ELISA as a reference test

As no study was carried out using comparative studies of NS 1 detection by FIA, Rapid ICT and NS 1 ELISA, can't compare with others.

Subhamoy Pal et al., states that rapid ICT is simple, easy and less time will be required, although NS 1 ELISA is superior with better sensitivity requiring trained personnel and special equipments. Considering NS 1 ELISA as a reference test in this study, rapid ICT gives $76 \%$ positive predictive value, stating that false positives more by rapid ICT. Meng Ling Moi et al., (2013) and Seok Mui Wang et al., (2010) states that NS 1 ELISA is useful, sensitive, specific and promising tool for early diagnosis of dengue viral infection. FIA is the test, which requires less time than NS 1 ELISA and its sensitivity is $100 \%$, specificity is $98.38 \%$, positive predictive value is $97.43 \%$ and negative predictive value is $100 \%$ which states that NS 1 Microwell ELISA and FIA results are very much comparable. 
Tables $1-6$ show the following findings.

In present study, 50 (25\%) samples were positive for NS1 by rapid ICT, which is comparable with studies of Ronni Mol (27.8\%), Pramiladevi et al., (27.27\%), Jigna Karia et al., (20.35\%) and with slight deviation with Badave et al., (16.51\%) and Deora et al., (15.6\%)

In present study, 19\% samples were positive by NS 1 Microwell ELISA, while Ronni Mol showed $27.8 \%$ positive cases.
Present study showed that majority of cases (i.e. 33 and 69 of dengue suspected cases) belong to age group 11-20 and 21-30 yrs.

This was comparable to other studies of Ronni Mol.

The disease was predominantly seen in males (72\%) than females (38\%) i.e., 1.8:1 which was corresponding to the other studies of Ronni Mol, males (59\%) than females (41\%) i.e. 1.4:1 and Jigna Karia et al., males (67\%) and females (32\%) i.e. $2: 1$.

Table.1 Comparison of NS 1 detection by rapid ICT and NS 1 Microwell ELISA

\begin{tabular}{|l|l|l|c|c|}
\hline \begin{tabular}{l} 
ELISA $\begin{array}{c}\text { Rapid ICT } \\
\downarrow\end{array}$ \\
\cline { 1 - 2 } NS 1 POSITIVE
\end{tabular} & NS 1 POSITIVE & NS1 NEGATIVE & Chi-square & P-value \\
\hline NS 1 NEGATIVE & 00 & 12 & \multirow{2}{*}{141} & $\begin{array}{c}<0.0001 \\
\mathrm{~S}\end{array}$ \\
\hline Total (200) & 38 & 150 & & 162 \\
\hline
\end{tabular}

$\mathrm{P}$-value $\mathrm{S}=$ significant.

From 50 positive samples by rapid ICT, 38 samples were positive and 12 were negative by Microwell ELISA.

Table. 2 Comparison of NS 1 detection by FIA and NS 1 Microwell ELISA

\begin{tabular}{|c|c|c|c|c|}
\hline $\begin{array}{l}\text { ELISA } \longrightarrow \\
\text { FIA } \\
\downarrow\end{array}$ & NS 1 POSITIVE & NS 1 NEGATIVE & Chi-square & $\mathrm{P}$-value \\
\hline NS 1 POSITIVE & 38 & 01 & \multirow{3}{*}{194} & \multirow{3}{*}{$\begin{array}{c}<0.0001 \\
\mathrm{~S}\end{array}$} \\
\hline NS 1 NEGATIVE & 00 & 161 & & \\
\hline Total (200) & 38 & 162 & & \\
\hline
\end{tabular}

$\mathrm{P}$-value $\mathrm{S}$ = significant.

From 50 positive samples by rapid ICT, 39 samples were positive and 11 were negative by FIA.

Table.3 Parameters of interest for Rapid ICT and FIA considering NS 1 ELISA as a reference test.

\begin{tabular}{|l|l|l|}
\hline & Rapid ICT & FIA \\
\hline Sensitivity & $100 \%$ & $100 \%$ \\
\hline Specificity & $80.64 \%$ & $98.38 \%$ \\
\hline Positive predictive value & $76 \%$ & $97.43 \%$ \\
\hline Negative predictive value & $100 \%$ & $100 \%$ \\
\hline
\end{tabular}

FIA test is more specific and having positive predictive value of $97.43 \%$ which states that it is more reliable than rapid ICT. 
Table.4 Age wise distribution of cases with reference to sex

\begin{tabular}{|l|l|l|l|}
\hline Age & Male & Female & Total cases \\
\hline 0 to 10 & $15(12.93 \%)$ & $07(8.3 \%)$ & 22 \\
\hline 11 to 20 & $20(17.24 \%)$ & $13(15.4 \%)$ & 33 \\
\hline 21 to 30 & $36(31.03 \%)$ & $33(39.28 \%)$ & 69 \\
\hline 31 to 40 & $11(9.48 \%)$ & $08(9.5 \%)$ & 19 \\
\hline 41 to 50 & $12(10.34 \%)$ & $13(15.47 \%)$ & 25 \\
\hline$>50$ & $22(18.96 \%)$ & $10(11.90 \%)$ & 32 \\
\hline Total & $116(100 \%)$ & $84(100 \%)$ & 200 \\
\hline
\end{tabular}

Present study showed that majority of cases (i.e. 33 and 69 of dengue suspected cases) belong to age group 11-20 and 21-30 yrs.

Table.5 Sex wise distribution of dengue positive and negative cases

\begin{tabular}{|l|l|l|l|}
\hline Sex & Dengue positive & Dengue negative & Total \\
\hline Male & $36(72 \%)$ & $80(53.33 \%)$ & 116 \\
\hline Female & $14(38 \%)$ & $70(46.66 \%)$ & 84 \\
\hline Total & 50 & 150 & 200 \\
\hline
\end{tabular}

The disease was predominantly seen in males (72\%) than females (38\%) i.e 1.8:1

Table.6 Comparison of NS 1 Antigen by rapid ICT and NS 1 Ag ELISA

\begin{tabular}{|l|l|l|}
\hline Test & NS 1 Ag Positive & Percentage \\
\hline FIA & 39 (out of 200) & $19.5 \%$ \\
\hline NS 1 Ag ELISA & 38 (out of 200) & $19 \%$ \\
\hline Rapid ICT & 50 (out of 200) & $25 \%$ \\
\hline
\end{tabular}

In present study, 39 (19.5\%) samples were positive by FIA, which is comparable with NS 1 ELISA 38 (19\%) in same study.

\begin{tabular}{|c|c|c|c|c|c|}
\hline Sr. No & Year & Author & Total samples & $\begin{array}{l}\text { NS } 1 \text { by rapid } \\
\text { ICT }\end{array}$ & NS 1 by ELISA \\
\hline 1 & 2015 & Ronni Mol P & 90 & $25(27.8 \%)$ & $25(27.8 \%)$ \\
\hline 2 & 2015 & $\begin{array}{l}\text { Pooja S. Deora et } \\
\text { al., }\end{array}$ & 288 & $45(15.6 \%)$ & - \\
\hline 3 & 2015 & $\begin{array}{l}\text { Gitanjali } \\
\text { Badave } \text { et al., }\end{array}$ & 327 & $54(16.51 \%)$ & - \\
\hline 4 & 2013 & Pramiladevi et al., & 66 & $18(27.27 \%)$ & - \\
\hline 5 & 2011 & Jigna Karia et al., & 280 & $57(20.35 \%)$ & - \\
\hline 6 & 2016 & This study & 200 & $50(25 \%)$ & $38(19 \%)$ \\
\hline
\end{tabular}


It indicates that male predominance than female and commonest age group affected (11 to 30), disease is more transmitted at work place.

ELISA is as good as gold standard tests but it is time consuming and technical expertisation is required.

ICT is less time consuming, easy to perform but it may give false positive results.

FIA is less time consuming and easy to perform whereas Microwell ELISA is time consuming and require highly technical expertise.

NS 1 Microwell ELISA and FIA results are very much comparable in relation with sensitivity, specificity, positive predictive value, and negative predictive value.

Hence for routine laboratories with limited resources one can use FIA test over Rapid ICT for early diagnosis of acute dengue infection

\section{Limitations}

More studies are required to assess the performance of FIA test device and that too, on a bigger sample size. Also this should be correlated with RT PCR/viral isolation / paired analysis of $\operatorname{IgM}$ and $\operatorname{IgG}$ titers by ELISA.

Study should include day of fever, platelet counts, symptoms of patients, so can correlate with time and conditions of patients.

\section{Acknowledgement}

Authors are thankful to Dean, M.G.M. Medical College, Aurangabad for granting the permission for this work. Authors are also thankful to the J. Mitra and Company for providing kits of ELISA and FIA for the study.

\section{References}

1. Ronni Mol P. 2010. Seroprevalence and Comparison of Rapid Immnunochromatographic Test and ELISA for the Detection of NS 1 Antigen for the Early Diagnosis of Dengue Fever" International Journal of Pharmacy \& Biological Sciences. 5 (2): 123 - 129

2. Pooja. S. Deora (Kaswa), Manjushree. H. Bhalchandra, Vijay M. Mulay "Early Diagnosis Of Dengue-Need Of The Hour" National Journal of Medical Sciences, January 2015, Volume IV, No. 1

3. Meng Ling Moi, et al "Detection of Dengue Virus Nonstructural Protein 1 (NS 1) by Using ELISA as a Useful Laboratory Diagnostic Method for Dengue Virus Infection of International Travelers" Journal of Travel Medicine 2013; Volume 20 (Issue 3): 185-193

4. Gitanjali K Badave, P.Sai Swaroop and P.Nageswara Rao "Importance of NS 1 Antigen detection and its association with platelets count for early diagnosis of dengue virus infection" International Journal of Current Microbiology \& Applied Sciences ISSN: 2319-7706 Volume 4 Number 3 (2015) pp. 779 784

5. Subhamoy Pal et al, Evaluation of Dengue NS 1 Antigen Rapid Tests and ELISA Kits Using Clinical Samples. 9 (11) 113411. 
6. Seok Mui Wang and Shamala Devi Sekaran. 2010. Evaluation of a Commercial SD DengueVirus NS 1Antigen Capture Enzyme - Linked Immunosorbant Assay Kit for Early Diagnosis of Dengue Virus Infection. Journal of Clinical Microbiology, 2793 2797

7. Jigna Karia et al. 2011. Evaluation of Commercial Newer Rapid Test For Detection of Early Acute Dengue Infection. National Journal of Medical Research, 1 (2).

8. Lyda Osorio et al. 2010. Comparision of the disgnostic accuracy of commercial NS 1 - based diagnostic tests for early dengue infection. Virology Journal. $7: 361$.
9. Dr. Pramiladevi R., Dr. Kaivalya, Dr. Shreeram Kora. 2013. Study of Rapid Serological Tests for Diagnosis of Dengue. Scholars Journal of Applied Medical Sciences (SJAMS); 1(5):548551

10. Handbook of Clinical Management of Dengue, WHO.

11. Pack insert of Dengue NS 1 Ag Quanti Card. J. Mitra \& Co. Pvt. Ltd, New Delhi, India.

12. Pack insert of Dengue Day 1 Test. J. Mitra \& Co. Pvt. Ltd, New Delhi, India.

13. Pack insert of Dengue NS $1 \mathrm{Ag}$ Microlisa. J. Mitra \& Co. Pvt. Ltd, New Delhi, India.

\section{How to cite this article:}

Pohekar, J.A., M.H. Bhalchandra, H.S. Ghogre and Pathrikar, T.G. 2017. Evaluation and Comparison of Currently Available Fluorescence Immunoassay (FIA) Test with Rapid Immuno Chromatographic Test (ICT) Considering NS 1 ELISA as a Reference Test. Int.J.Curr.Microbiol.App.Sci. 6(11): 506-513. doi: https://doi.org/10.20546/ijcmas.2017.611.061 